\title{
MONITORING BIMBINGAN SKRIPSI ONLINE PADA SEKOLAH TINGGI MANAJEMEN INFORMATIKA DAN KOMPUTER (STMIK) PALANGKA RAYA
}

\author{
Utariani $^{1}$, Herkules ${ }^{2}$ \\ Teknik Informatika, Sekolah Tinggi Manajemen Informatika dan Komputer (STMIK) \\ Palangka Raya \\ Jl. G.Obos No.114, Palangka Raya 73112 Kalimantan Tengah \\ e-mail ${ }^{1}$ : utariani@gmail.com \\ e-mail ${ }^{2}: \underline{\text { herkules11282@gmail.com }}$
}

\begin{abstract}
The problem of this research is how to design and build a web-based application to make the process of thesis guidance. This app aims to help the process of guidance and help students who are taking the thesis and lecturers also may correct student thesis, so that the process runs smoothly guidance to complete. Further, the application also helps faculty in monitoring students in conducting guidance

The methods used in this research for observational data collection is interview, and literature, for software development methods we using the waterfall model, software testing methods using Black Box Testing and methods for analysis system weaknesses using PIECES.

This research has been successfully implemented an Application Monitoring Guidance thesis on the School of Information Management and Computer Palangkaraya Based Web using codeigniter 3.0 and has been successfully tested against the results of the implementation.The application can provide convenience for students who are doing a thesis on STMIK Palangka raya.
\end{abstract}

Keyword : Web Application, Monitoring Thesis, Framework, CodeIgniter, PHP, MySQL.

\section{PENDAHULUAN}

Teknologi informasi yang

berkembang pesat dewasa ini telah mendorong percepatan diberbagai bidang, hal ini juga yang menyebabkan munculnya kemajuan pada perangkat lunak dan diimbangi pula dengan kemjuan pada kecanggihan teknologi beserta perangkat kerasnya. Misalnya pada bidang pendidikan seperti Universitas atau
Perguruan Tinggi juga membutuhkan dukungan teknologi informasi dalam peningkatan mutu pelayanan terhadap proses pendidikan. Penggunaan aplikasi online saat ini semakin banyak, hal ini menjadi salah satu alasan mengapa diperlukannya aplikasi berbasis web dalam proses bimbingan skripsi.

Skripsi atau Tugas Akhir merupakan tugas final yang harus diselesaikan oleh 
seorang mahasiswa yang akan lulus dari jenjang pendidikan strata satu atau diploma di perguruan tinggi. Dalam pengerjaan skripsi, mahasiswa perlu melakukan konsultasi atau bimbingan kepada dosen pembimbing yang telah ditentukan oleh Ketua Jurusan. Hal ini bertujuan untuk membantu mahasiswa dalam mengerjakan skripsi lebih terarah dan lebih fokus agar hasil yang diharapkan dapat tercapai. Dalam prakteknya, aktifitas bimbingan skripsi atau tugas akhir ini dilakukan dengan diskusi, tanya jawab, pemberian masukan dan aktifitas lainnya.

Di STMIK Palangka Raya bimbingan skripsi dilakukan mahasiswa dengan bertemu secara langsung dengan dosen pembimbingnya. Namun

kadangkala proses bimbingan terjadi kendala seperti dosen pembimbingnya sedang keluar kota atau sedang ada kesibukan lain sehingga mahasiswa untuk melakukan bimbingan menjadi tertunda. Dengan adanya aplikasi ini diharapkan menjadi salah satu solusi yang dapat membantu proses bimbingan dan membantu mahasiswa yang sedang mengambil skripsi dan dosen juga tetap bisa mengoreksi skripsi mahasiswa, sehingga proses bimbingan berjalan lancar hingga selesai. Selain untuk melakukan bimbingan, aplikasi ini juga digunakan untuk memonitoring mahasiswa yang sedang bimbingan, dengan begitu dosen dapat melihat keaktifan mahasiswa dalam melakukan bimbingan.

\section{KAJIAN TEORI}

\section{Aplikasi}

Perangkat lunak aplikasi (application software), yaitu program yang ditulis dan diterjemahkan oleh language software untuk menyelesaikan suatu aplikasi tertentu (Jogiyanto, 2005:231).

Aplikasi berasal dari kata application yang artinya penerapan,lamaran,penggunaan. Secara istilah aplikasi adalah: program siap pakai yang direkap untuk melaksanakan suatu fungsi bagi pengguna atau aplikasi yang lain dan dapat digunakan oleh sasaran yang dituju.

\section{Monitoring}

Monitoring merupakan pengidentifikasiaan kesuksesan atau kegagalan secara nyata maupun potensial sedini mungkin dan sewaktu-waktu bisa menyelesaikan operasioanlnya dengan tujuan meninjau kemajuan dan mengusulkan langkah supaya dijalankan untuk meraih dan mewujudkan tujuan untuk menolong manusia dalam 
melaksanakan tugas tertentu (Moritian, dkk., 2013:67).

Adapun beberapa tujuan dari monitoring adalah mengkaji apakah kegiatan-kegiatan yang dilaksanakan telah sesuai dengan rencana, mengidentifikasi masalah yang timbul agar langsung dapat diatasi, melakukan penilaian apakah pola kerja dan manajemen yang digunakan sudah tepat untuk mencapai tujuan, mengetahui kaitan antara kegiatan dengan tujuan untuk memperoleh ukuran kemajuan.

\section{Bimbingan Online}

Bimbingan memiliki arti sebagai petunjuk (penjelasan) cara mengerjakan sesuatu, tuntunan atau pimpinan. Sedangkan kata online berasal dari bahasa inggris yang dapat diartikan sebagai suatu keadaan yang sedang menggunakan jaringan, terhubung dalam jaringan, satu perangkat dengan perangkat lainnya yang terhubung sehingga bisa saling berkomunikasi (Dwiyani, 2013:2).

Adapun tujuan dari bimbingan yaitu, merencanakan kegiatan penyelesaian studi, perkembangan karir serta kehidupannya di masa yang akan datang, mengembangkan seluruh potensi yang dimilikinya seoptimal mungkin, menyesuaikan diri dengan lingkungan pendidikan, lingkungan masyarakat serta lingkungan kerjanya, mengatasi hambatan dan kesulitan yang dihadapi dalam studi, penyesuaian dengan lingkungan pendidikan, masyarakat, maupun lingkungan kerja

\section{Website}

Web Site atau Website (ditulis rapat) adalah bagian dari suatu web, dan biasa disingkat dengan Site saja. Tetapi ada juga yang menyebutnya dengan Homepage (Pardosi, 2001:15).

Situs Web (bahasa Inggris : web site) atau sering disingkat dengan istilah situs adalah sejumlah halaman web yang memiliki topik saling terkait, terkadang disertai pula dengan berkas-berkas gambar, video, atau jenis-jenis berkas lainnya (Dipanegara, 2011:1).

\section{HTML}

HTML kependekan dari Hyper Text Markup Language, dan dokumen HTML merupakan teks murni yang sering disebut dengan web page. Dokumen HTML berekstensi ".htm" atau ".html" (MADCOMS, 2009:21).

HTML merupakan dasar atau tulang punggung dalam pembuatan sebuah web. Dalam setiap file HTML akan selalu didahului dengan tag $\langle$ HTML $\rangle$. Tag ini akan membuat web browser mencoba untuk membaca file yang ada di dalam tag 
tersebut untuk ditampilkan dalam webbrowser (Aditya, 2011:34).

\section{PHP}

PHP merupakan singkatan dari PHP Hypertext Preprocessor. Ia merupakan bahasa berbentuk skrip yang ditempatkan dalam server dan diproses di server. Hasilnya yang akan dikirimkan ke klien, tempat pemakai menggunakan browser (Kadir, 2008:2).

\section{MySQL}

MySQL adalah sebah perangkat lunak sistem manajemen basis data SQL (bahasa Inggris: database management system) atau DBMS yang multithread, multiuser, dengan sekitar 6 juta instalasi diseluruh dunia. MySQL AB membuat MySQL tersedia sebagai perangkat lunak gratis dibawah lisensi GNU General Public License (GPL) (Aditya, 2011:61).

\section{Framework}

Framework diartikan sebagai kumpulan potongan-potongan program (kelas dan fungsi) yang disusun dan diorganisasikan sedemikian rupa, sehingga dapat digunakan kembali untuk membantu membuat aplikasi utuh tanpa harus membuat semua kodenya dari awal (Basuki, 2014:12).

Framework merupakan suatu kerangka kerja yang telah terinclude dengan kumpulan perintah dan fungsi dasar yang saling terintegrasi satu dengan yang lain sehingga dalam pengerjaan suatu aplikasi.

\section{CodeIgniter}

CodeIgniter (CI) adalah sebuah framework yang digunakan untuk membuat sebuah aplikasi berbasis web yang disusun dengan menggunakan bahasa PHP. Di dalam CI ini terdapat beberapa macam kelas yang berbentuk library dan helper yang berfungsi untuk membantu pemrograman dalam mengembangkan aplikasinya (Basuki, 2014:23).

\section{Object Oriented Programming}

Pemrograman Berorientasi Objek (OOP) merupakan paradigma pemrograman yang menganggap semua benda adalah objek, yaitu menganggap segala sesuatu dalam bahasa pemrograman adalah objek, bahkan variabel pun dianggap sebagai suatu objek.Teknik pemrograman OOP bisa disebut juga sebagai teknik pemrograman modern (Saputra, 2012:15).

\section{Twitter Bootstrap}

Twitter Bootsrap adalah sebuah alat bantu untuk membuat sebuah tampilan halaman website yang dapat mempercepat pekerjaan seorang pengembang website ataupun pendesain 
halaman website. Sesuai namanya, website yang dibuat dengan alat bantu ini memiliki tampilan halaman yang sama / mirip dengan tampilan Twitter atau desainer juga dapat mengubah tampilan halaman website sesuai dengan kebutuhan.

\section{Unified Modelling Language}

Unified Modelling Language "

bahasa standar untuk penulisan cetak biru perangkat lunak. UML dapat digunakan untuk memvisualisasikan, menentukan, mengonstruksi dan mendokumentasikan artifak-artifak suatu sistem softwareintensive” (Pressman, 2010:987).

UML (Unified Modeling Language) adalah 'bahasa' pemodelan untuk sistem atau perangkat lunak yang berparadigma 'berorientasi objek'. Pemodelan (modeling) sesungguhnya digunakan untuk penyederhanaan permasalahan-permasalahan yang kompleks sedemikian rupa sehingga lebih mudah dipelajari dan dipahami (Nugroho, 2010:6).

Pemodelan $U M L$ digambarkan dengan :

a. Use Case diagram adalah diagram yang menggambarkan actor, use case dan relasinya sebagai suatu urutan tindakan yang memberikan nilai terukur untuk aktor. Sebuah use case digambarkan sebagai elips horizontal dalam suatu diagram UML use case.

b. Class Diagram Class diagram menggambarkan struktur statis dari kelas dalam sistem dan menggambarkan atribut, operasi dan hubungan antara kelas. Class diagram membantu dalam memvisualisasikan struktur kelaskelas dari suatu sistem dan merupakan tipe diagram yang paling banyak dipakai. Selama tahap desain, class diagram berperan dalam menangkap struktur dari semua kelas yang membentuk arsitektur sistem yang dibuat.

c. Activity diagram adalah diagram yang menggambarkan aktifitasaktifitas, objek, state, transisi state dan event. Dengan kata lain kegiatan diagram alur kerja menggambarkan perilaku sistem untuk aktivitas.

d. Sequence diagram menjelaskan interaksi objek yang disusun berdasarkan urutan waktu. Secara mudahnya sequence diagram adalah gambaran tahap demi tahap, termasuk kronologi (urutan) perubahan secara logis yang seharusnya dilakukan untuk 
e. menghasilkan sesuatu sesuai dengan use case diagram.

13. Analisis PIECES

Tahap analisis sistem dengan PIECES Analysis, data yang sudah terkumpul kemudian di analisis untuk menentukan berbagai kebutuhan yang diperlukan dalam melakukan pengembangan sistem seperti performance, informasi, economic, control, efficiency, service, analisis kebutuhan sistem, analisis kebutuhan keluaran sistem dan analisis kebutuhan masukan yang diperlukan pada sistem yang akan dibangun.

\section{Black-box Testing}

Pengujian black-box berfokus pada persyaratan fungsional perangkat lunak. Dengan demikian, pengujian black-box memungkinkan perekayasa perangkat lunak mendapatkan serangkaian kondisi input yang sepenuhnya menggunakan semua persyaratan fungsional untuk suatu program (Pressman, 2002:551).

\section{Adobe Dreamweaver CS6}

Adobe Dreamweaver CS6 adalah software terkemuka untuk membangun dan mengedit web dengan menyediakan kemampuan visual dan tingkat kode, yang dapat digunakan untuk membuat website berbasis standar dan desain untuk desktop, mobile, smartphone, tablet, dan perangkat lainnya (MADCOMS, 2011:3).

\section{6. $X A M P P$}

XAMPP adalah merupakan paket PHP dan MySQL berbasis open source yang dapat digunakan sebagai tool pembantu pengembangan aplikasi berbasis PHP. XAMPP mengombinasikan beberapa paket perangkat lunak berbeda kedalam satu paket (Riyanto, 2011:4).

\section{StarUML}

StarUML adalah sebuah proyek open source untuk pengembangan secara cepat, fleksibel, extensible, featureful, dan bebas tersedia. Tujuan dari proyek StarUML adalah untuk membangun sebuah alat pemodelan perangkat lunak dan juga platform yang menarik adalah pengganti alat UML (Iswari,2015:73).

\section{Balsamiq Mockup}

Balsamiq mockup adalah program aplikasi yang digunakan dalam pembuatan tampilan user interface sebuah aplikasi. Software ini sudah menyediakan tools yang dapat memudahkan dalam membuat desain prototyping aplikasi yang akan kita buat. Software ini berfokus pada konten yang ingin digambar dan fungsionalitas yang dibutuhkan oleh pengguna (Attaufiq, 2014:73). 


\section{METODE PENELITIAN}

Penelitian ini dilakukan dengan metode sebagai berikut :

- Studi Observasi, yaitu peninjauan secara langsung dilapangan atau lokasi penelitian yaitu STMIK Palangkaraya mengenai proses bimbingan yang sedang berjalan.

- Interview (wawancara), penulis melakukan tanya jawab kepada pihak Jurusan Teknik Informatika di STMIK Palangkaraya guna melengkapi data yang digunakan untuk penelitian.

- Studi pustaka, yaitu dengan mempelajari buku-buku atau referensireferensi yang ada berkaitan dengan penelitian.

- Analisis Kebutuhan

Dalam menganalisa kebutuhan penulis meninjau langsung sistem yang berjalan di STMIK Palangkaraya, setelah menganalisa dan menemukan permasalahannya maka penulis menetapkan kebutuhan-kebutuhan apa saja yang akan digunakan pada sistem untuk membantu menyelesaikan permasalahan yang ada.

- Desain Sistem dan Desain Program. Dalam tahap ini yang akan dilakukan penulis adalah merancang pemodelan system dan desain interface program agar alur dari proses program tersebut jelas. Untuk pemodelan sistem penulis menggunakan pemodelan sistem Unified Modelling Language (UML) yaitu : use case diagram, class diagram, activity diagram, sequence diagram.

- implementasi dan testing.

Dalam tahap ini yang akan penulis lakukan adalah membuat aplikasi menggunakan bahasa pemrograman PHP. Setelah program selesai dibuat maka yang akan dilakukan penulis adalah testing dengan menggunakan black box testing, ini dilakukan untuk menguji jalannya aplikasi sudah sesuai dengan yang diharapkan atau belum. Testing dilakukan oleh Ketua Jurusan Teknik Informatika.

- Integrasi dan Pengujian Sistem

Dalam tahap ini yang akan penulis lakukan adalah menggabungkan unitunit program dan mengujinya. Setelah di ujicoba dan hasilnya sudah sesuai dengan kebutuhan maka selanjutnya pengujian system. Untuk menguji system, yang akan dilakukan adalah menjalankan sistem di browser dengan 
pengoperasian yang dilakukan oleh user.

- pemeliharaan. pada tahap ini aplikasi telah selesai dan dapat dikembangkan sesuai dengan permintaan user yaitu Dosen, dan Mahasiswa pada STMIK Palangkaraya.

\section{HASIL DAN PEMBAHASAN}

Analisis yang digunakan untuk menganalisa sistem dalam mengenali penyebab masalah yaitu dengan metode PIECES (Performance, Information, Economic, Control, Efficiency, Service). Dengan analisa tersebut, maka dapat diperoleh beberapa penyebab masalah yang akhirnya dapat disimpulkan dengan jelas dan lebih spesifik pada titik permasalahannya sehingga membantu dalam membuat perancangan sistem baru yang lebih baik.

Tabel 1. Anilis PIECES

\begin{tabular}{|l|l|l|}
\hline PIECES & $\begin{array}{l}\text { Hasil Analisis } \\
\text { Terhadap } \\
\text { Sistem Lama }\end{array}$ & $\begin{array}{l}\text { Hasil Yang } \\
\text { Diharapkan } \\
\text { Dari Sistem } \\
\text { baru }\end{array}$ \\
\hline $\begin{array}{l}\text { Performance } \\
\text { (Kinerja) }\end{array}$ & $\begin{array}{l}\text { Mahasiswa } \\
\text { harus bertemu } \\
\text { dosen } \\
\text { pembimbing }\end{array}$ & $\begin{array}{l}\text { Mahasiswa } \\
\text { tidak harus } \\
\text { bertemu dosen }\end{array}$ \\
\hline $\begin{array}{l}\text { Information } \\
\text { (Informasi) }\end{array}$ & $\begin{array}{l}\text { Dosen tidak } \\
\text { bisa melihat } \\
\text { keaktifan } \\
\text { mahasiswa } \\
\text { dalam } \\
\text { melakukan } \\
\text { bimbingan }\end{array}$ & $\begin{array}{l}\text { Dosen bisa } \\
\text { melihat } \\
\text { keaktifan } \\
\text { mahasiswa } \\
\text { dalam } \\
\text { melakukan } \\
\text { bimbingan } \\
\text { dalam history. }\end{array}$ \\
\hline $\begin{array}{l}\text { Economy } \\
\text { (Ekonomi) }\end{array}$ & $\begin{array}{l}\text { Jika ada } \\
\text { kesalahan } \\
\text { harus } \\
\text { memprint } \\
\text { kembali. }\end{array}$ & $\begin{array}{l}\text { Dapat } \\
\text { mengirim data } \\
\text { skripsi tanpa } \\
\text { memprint } \\
\text { terlebih } \\
\text { dahulu }\end{array}$ \\
\hline $\begin{array}{l}\text { Control } \\
\text { (Pengendalian } \\
\text { ) }\end{array}$ & $\begin{array}{l}\text { Bimbingan } \\
\text { dapat } \\
\text { terpantau }\end{array}$ & $\begin{array}{l}\text { Dosen dapat } \\
\text { mengirim } \\
\text { pesan untuk } \\
\text { mahasiswa }\end{array}$ \\
\hline Efficiency & Keterlambatan \\
Mempercepat \\
\hline
\end{tabular}

\begin{tabular}{|l|l|l|}
\hline (Efisiensi) & $\begin{array}{l}\text { dalam } \\
\text { menyelesaika } \\
\text { n skripsi }\end{array}$ & $\begin{array}{l}\text { proses } \\
\text { bimbingan }\end{array}$ \\
\hline $\begin{array}{l}\text { Service } \\
\text { (Pelayanan) }\end{array}$ & $\begin{array}{l}\text { Saat akan } \\
\text { bimbingan } \\
\text { terkadang } \\
\text { dosen sedang } \\
\text { sibuk } \\
\text { sehingga sulit } \\
\text { untuk } \\
\text { bertanya }\end{array}$ & $\begin{array}{l}\text { Disediakan } \\
\text { fasilitas } \\
\text { chatting untuk } \\
\text { mempermuda } \\
\text { h dosen } \\
\text { pembimbing } \\
\text { dan } \\
\text { mahasiswa } \\
\text { untuk } \\
\text { bertanya } \\
\text { jawab. }\end{array}$ \\
\hline
\end{tabular}

Tahap perancangan perangkat lunak merupakan proses yang berfokus pada beberapa atribut yang ada di perangkat lunak. Proses ini menerjemahkan kebutuhan ke dalam sebuah model perangkat lunak dan berdasarkan analisis sistem sebelumnya menghasilkan rancangan yang berisi UML, ERD (Entity Relationship Diagram) dan desain antar muka.

Dalam merancang proses pada aplikasi monitoring bimbingan skripsi peneliti menggunakan notasi UML sebagai case tool dalam merancang proses yang akan terjadi di dalam aplikasi, yakni dengan membuat use case diagram, class diagram, sequence diagram, dan activity diagram.

1) Use case diagram

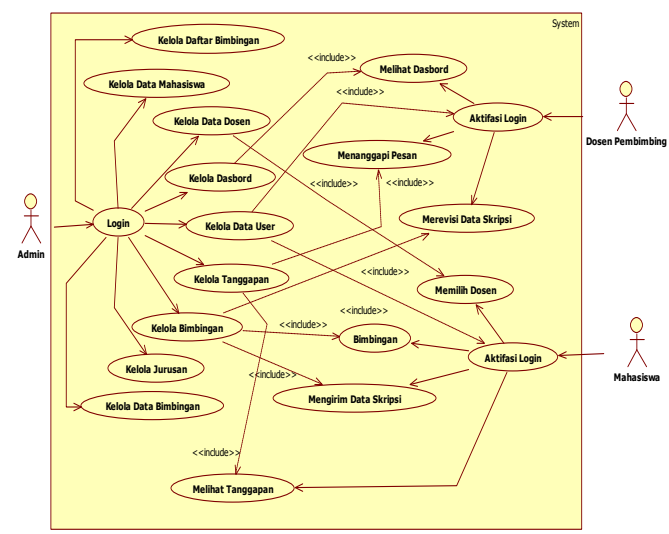

Gambar 1. Use case diagram

Pada Gambar 1 Use case diagram terdapat tiga aktor pengguna dalam aplikasi yang telah dibangun yaitu admin, 
dosen dan mahasiswa. Pada usecase tersebut admin memiliki peran untuk kelola data dosen, kelola data mahasiswa, kelola bimbingan, kelola data user, kelola tanggapan, kelola jurusan dan kelola dasbord. Sedangkan dosen pada aplikasi yang dibangun memiliki fungsi merevisi data skripsi, menanggapi pesan dan melihat dasbord. Untuk mahasiswa pada aplikasi ini dapat melakukan bimbingan, mengirim data skripsi dan melihat tanggapan

2) Class Diagram

Diagram kelas atau class diagram dibangun untuk mendeskripsikan jenisjenis objek dalam sistem dan berbagai macam hubungan statis yang terdapat diantara tiap class. Diagram kelas merupakan suatu diagram yang menggambarkan atau memvisualisasikan struktur sistem dari kelas-kelas serta hubungannya. Diagram kelas ini juga menampilkan interaksi dalam kelas-kelas tersebut, atribut, atribut apa yang dimiliki atau operasi/metode apa yang dimiliki kelas itu. Berikut adalah diagram class diagram aplikasi monitoring bimbingan skripsi :

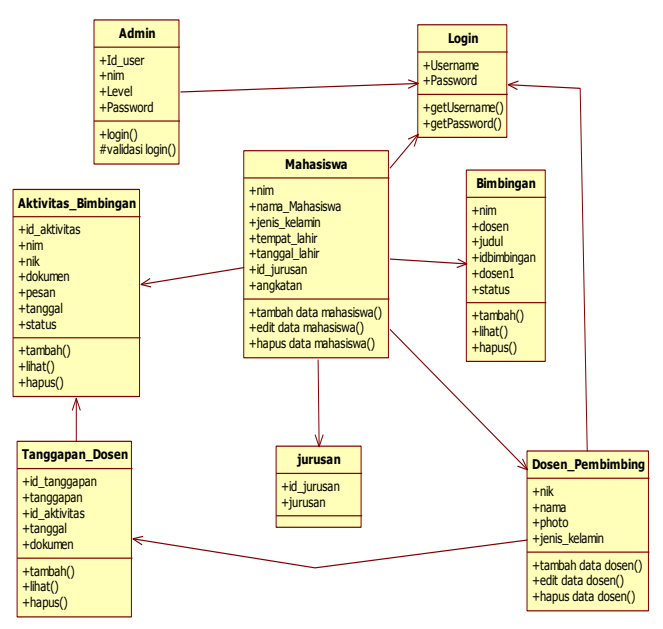

Gambar 2. Class diagram

\section{3)Desain basis data}

Entity Relationship Diagram (ERD) adalah notasi yang digunakan untuk melakukan aktivitas pemodelan data. Tujuan utama dari ERD adalah mewakili objek data dan hubungan mereka. Adapun bentuk Entity Relationship Diagram adalah sebagi berikut :

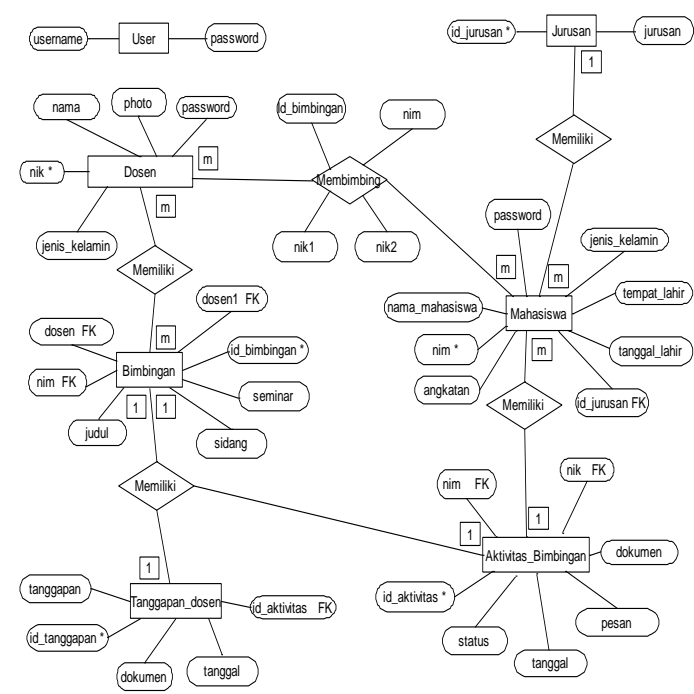

Gambar 3. ERD 
Dari ERD diatat ditransformasikan ke bentul relasi antar tabel :

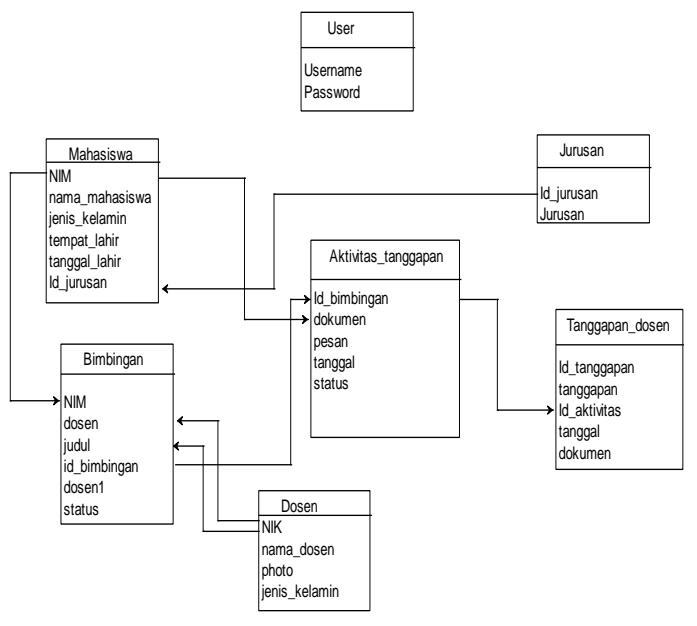

\section{Gambar 4. Relasi Antar Tabel}

Hasil dari Aplikasi Monitoring Bimbingan Skripsi Pada Sekolah Tinggi Manajemen Informatika dan Komputer (STMIK) Palangka Raya terdiri dari beberapa output sistem sebagai berikut :

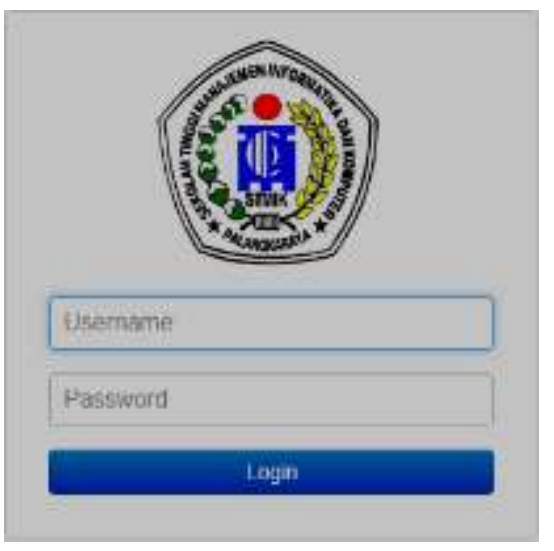

5. Tampilan Halaman Login

\section{a. Mahasiswa}

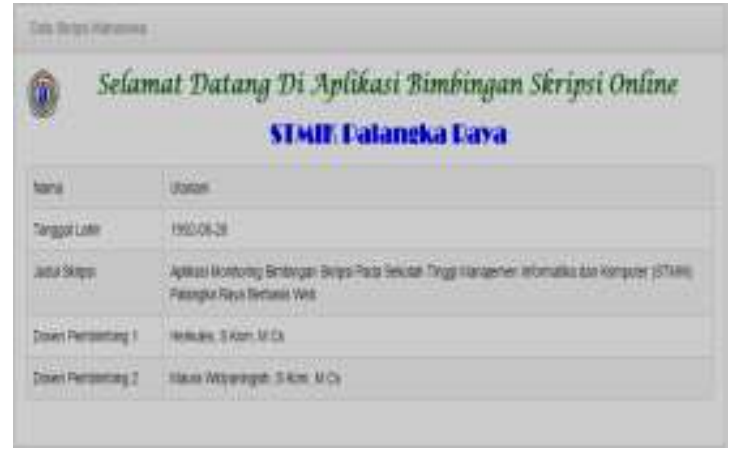

Gambar 6. Tampilan Menu Halaman

\section{Depan}

Dalam Aplikasi Monitoring Bimbingan Skripsi Pada Sekolah Tinggi Manajemen Informatika dan Komputer (STMIK) Palangka Raya Berbasis Web mahasiswa dapat melakukan bimbingan dengan mengirimkan data skripsi dan pesan kepada dosen pembimbing. Berikut form bimbingan untuk mahasiswa melakukan bimbingan pada Gambar 7:

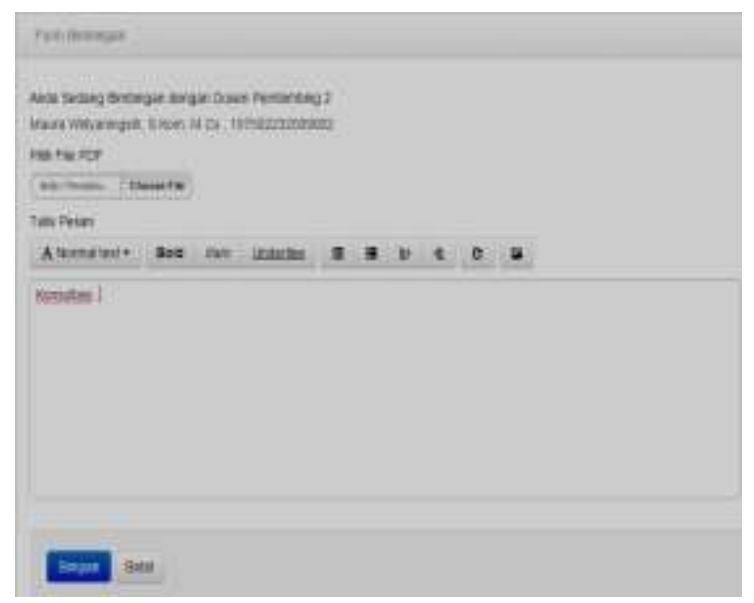

Gambar 7. Form Bimbingan

Setelah data skripsi direvisi, mahasiswa dapat mendownload dan melihat tanggapan dari dosen pembimbingnya seperti Gambar 8 . 


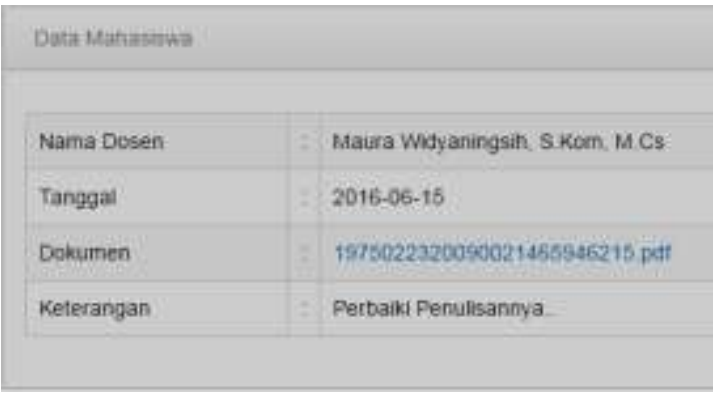

Gambar 8. Dokumen yang

didownload dan tanggapan dari dosen

Setelah melakukan bimbingan mahasiswa juga dapat mencetak kartu konsultasi di aplikasi ini seperti Gambar 9 .

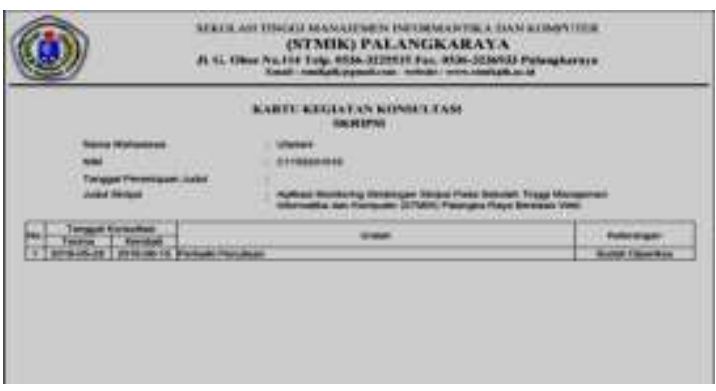

Gambar 9. Bukti Bimbingan yang dicetak

Mahasiswa

\section{b. Dosen}

Dalam Aplikasi Monitoring Bimbingan Skripsi Pada Sekolah Tinggi Manajemen Informatika dan Komputer (STMIK) Palangka Raya Dosen dapat melihat daftar mahasiswa yang sedang bimbingan seperti Gambar 10.

Kemudian dosen juga dapat melihat mahasiswa yang konsultasi serta dapat mendownload data skripsi yang akan dikoreksi seperti Gambar 11. Setelah data dikoreksi maka dosen akan mengirimkan kembali data skripsi ke mahasiswa dan dosen juga memberikan tanggapan seperti Gambar 12.

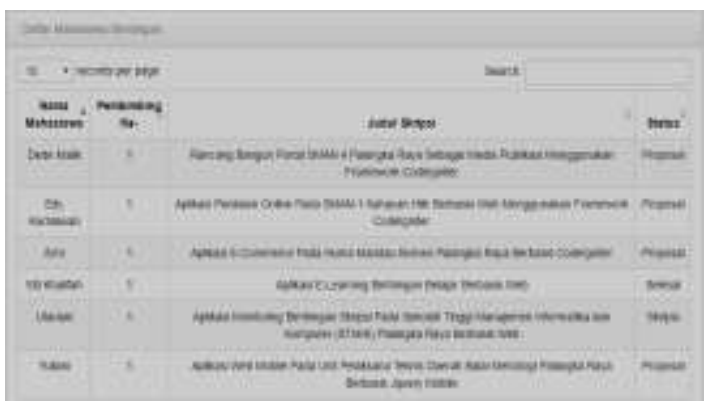

Gambar 10. Daftar Mahasiswa yang dapat dilihat dosen

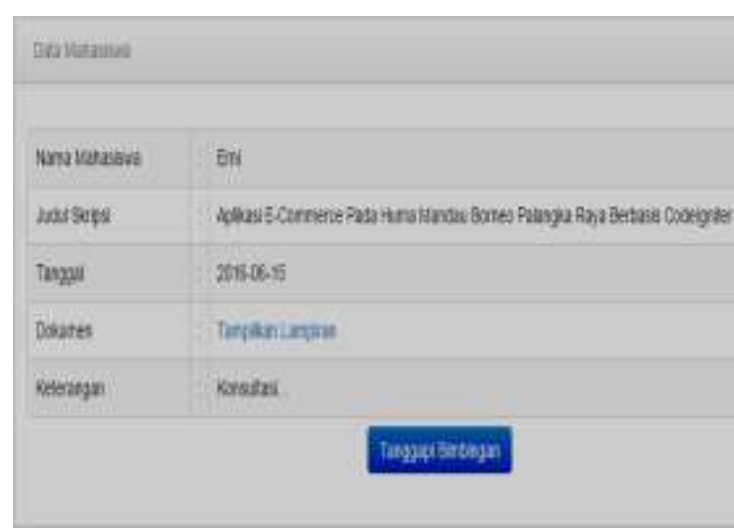

Gambar 11. Dokumen yang akan dikoreksi dosen

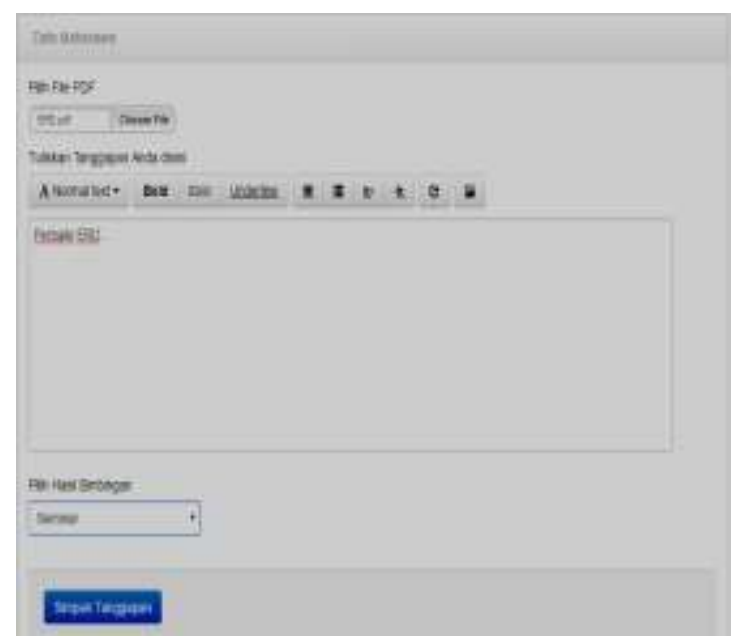

Gambar 12. Form Bimbingan Dosen untuk menanggapi pesan dari Mahasiswa Dosen juga dapat memantau mahasiswa yang aktif melakukan bimbingan dengan 
melihat bukti bimbingan selain itu bukti bimbingan juga dapat dicetak oleh dosen seperti Gambar 13.

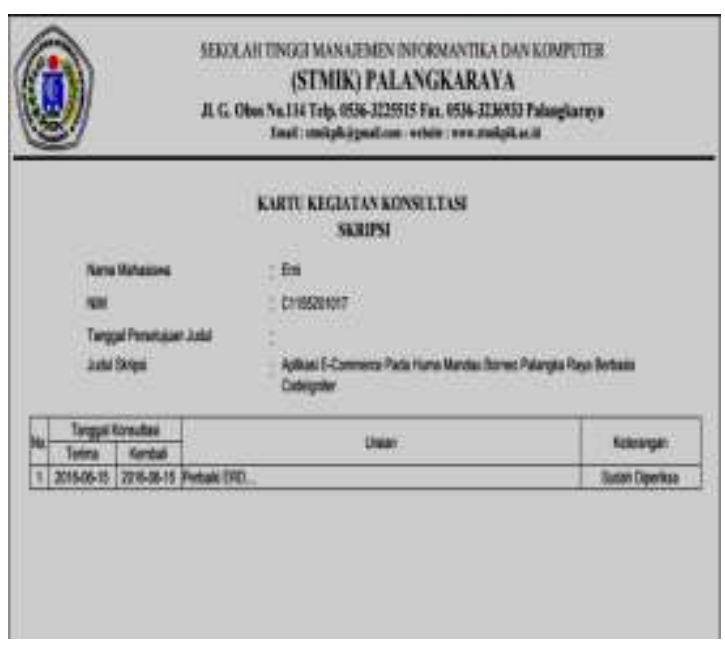

Gambar 13. History Mahasiswa

c. Admin

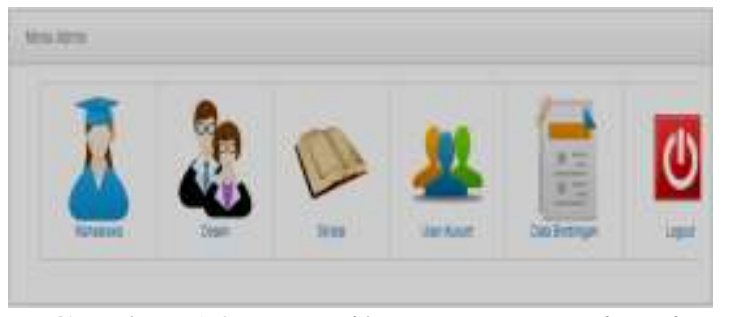

Gambar 14. Tampilan Menu Dasbord admin

Dalam Aplikasi Monitoring Bimbingan Skripsi Pada Sekolah Tinggi Manajemen Informatika dan Komputer (STMIK) Palangka Raya Berbasis Web admin dapat mencetak laporan jumlah bimbingan perdosen seperti Gambar 15.

Selain laporan jumlah bimbingan perdosen admin juga dapat melihat serta mencetak laporan jumlah bimbingan seluruh dosen perbulan seperti Gambar 16.

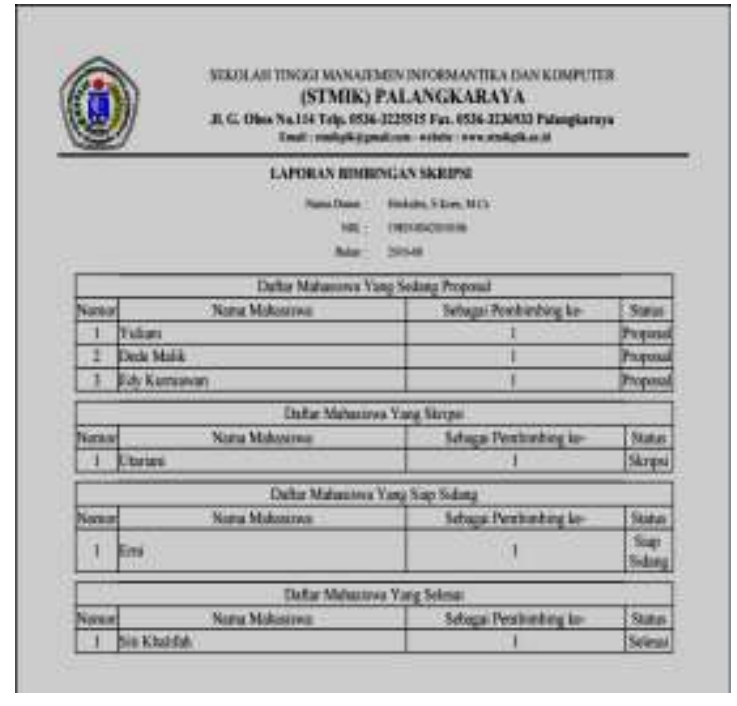

Gambar 15. Laporan Jumlah Bimbingan Perdosen

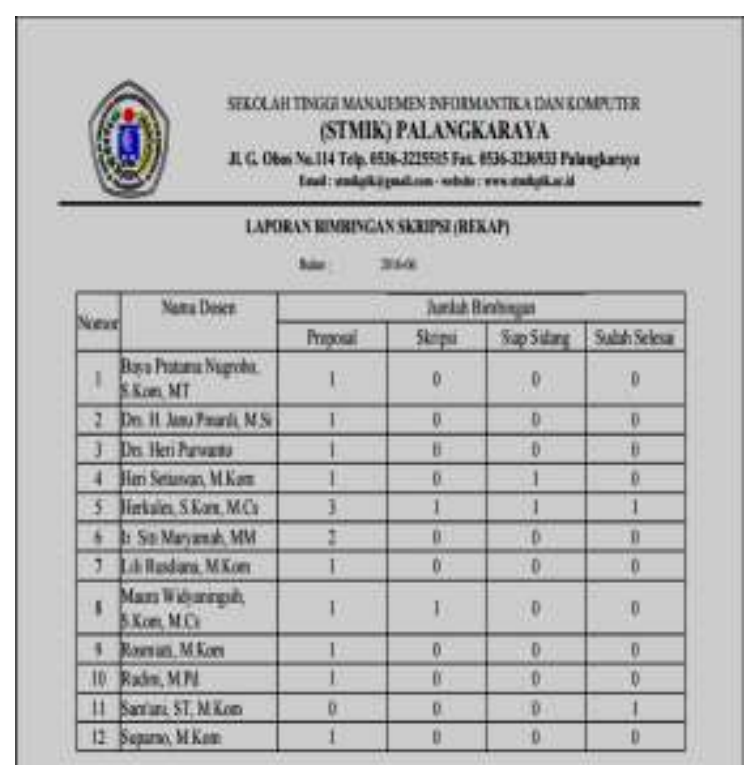

Gambar 16. Laporan Jumlah Bimbingan Perbulan

Admin juga dapat memantau keaktifan mahasiswa dalam melakukan bimbingan dengan melihat bukti bimbingan dan bukti bimbingan juga dapat dicetak oleh admin seperti gambar 17. 


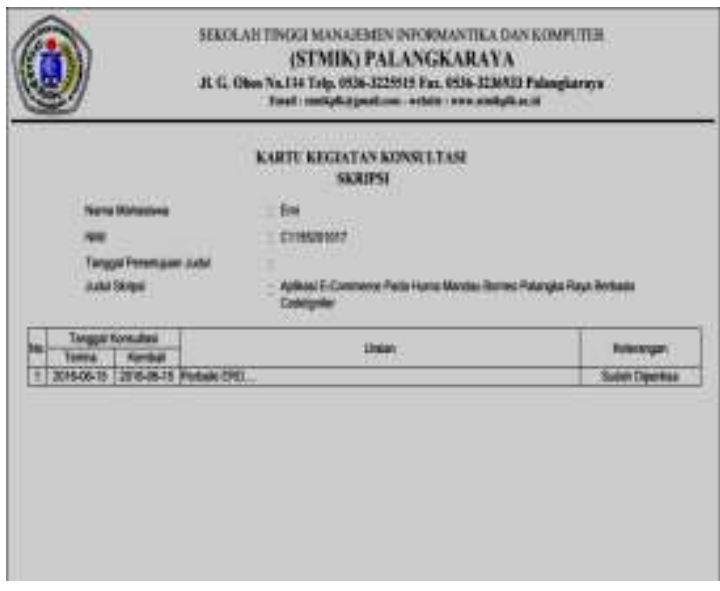

Gambar 17. Bukti Bimbingan Mahasiswa

\section{KESIMPULAN}

Dari uraian keseluruhan yang telah dikemukakan mulai dari proses analisis hingga implementasi system dapat diambil kesimpulan yaitu Aplikasi Monitoring Bimbingan Skripsi Pada Sekolah Tinggi Manajemen Informatika Dan Komputer (STMIK) Palangka Raya yang berhasil dibangun dapat memberi kemudahan kepada mahasiswa dan dosen dalam melakukan bimbingan meskipun tidak bertemu secara langsung, dosen dan pihak Jurusan dapat memonitoring mahasiswa dalam melakukan bimbingan agar proses pengerjaan Skripsi/Tugas Akhir mahasiswa dapat selesai tepat waktu.

\section{SARAN}

Aplikasi Monitoring Bimbingan Skripsi Pada Sekolah Tinggi Manajemen Informatika dan Komputer (STMIK)
Palangka Raya masih banyak kekurangan fasilitas seperti Chating dan video Streaming dalam membantu mempercepat proses bimbingan Skripsi/Tugas Akhir.

\section{DAFTAR PUSTAKA}

Aditya, N. A. 2011. Jago PHP \& MySQL, Dunia Komputer, Bekasi.

Aresuki, Dimas. 2014. Pengertian Twitter Bootstrap Fungsi Kelebihan dan Kekurangannya.

http://www.dimasaresuki.com/2014/06 /pengertian-twitter-bootstrapfungsi.html Diakses pada tanggal 14 April 2015.

Achyarudin, Y. dkk. 2013. Sistem Informasi Akademik Berbasis Android Pada STMIK Global Informatika Multi Data Palembang, 1-7.

Basuki, A. P. 2014. Proyek Membangun Website dengan CodeIgniter, Lokomedia, Yogyakarta.

Dipanegara, A. 2011. Langsung Jago Bikin Website-Gratis dengan Web, Agogos Publishing, Jakarta.

Dwiyani, A., 2013. Perancangan Sistem Pendukung Bimbingan Online Tugas Akhir Mahasiswa Program Studi Teknik Informatika, 1-5.

Guritno, S., dkk. 2011. Metodologi Penelitian Teknologi Informasi, ANDI OFFSET, Yogyakarta.

Jogiyanto H. M. 2005. Analisis \& Desain Sistem Informasi : Pendekatan Terstruktur Teori dan Praktik Aplikasi Bisnis, Andi, Yogyakarta. 
Jurnal Informatika Mulawarman, Volume

6 Nomor 1 bulan Februari 2011, Memahami Penggunaan UML (Unified Modelling Language), Haviluddin, 3-7.

Jurnal Algoritma, Volume 11 Nomor 1 2014 ISSN 2302-7339, Perancangan Aplikasi Penjualan SparepartPada Bengkel Fajar Motor Menggunakan Metode Berorientasi Objek, Muhammad Rangga Perkasa, dkk., 3. Jurnal Sistem Informasi, Volume 6 Nomor 2 bulan September 2011, Pembuatan Aplikasi Pengelolaan Tugas Akhir Online Berbasis Web Studi Kasus Jurusan Teknik Informatika UKM, Tjatur Kandaga dan Vinsensius Felix, 185-197.

Jurnal Sistem Informasi, JSIKA 2 2013, Analisis Kelayakan Investasi Dan Monitoring Usaha Budidaya Ikan Bandeng Secara Intensif Berbasis Web Di Sidayu Kabupaten Gresik, Dio Ichwandoko Moritian, dkk., 67. Jurnal Ultimatics, Volume VII Nomor 1 bulan Juni 2015, Review Perangkat Lunak StarUML Berdasarkan Faktor Kualitas McCall, Ni Made Satvika Iswari,73.

Jurnal Skripsi, 2014, Configuration Management System (CMS) Pada PT Radiant Utama Interinsco TBK, Ridwan Attaufiq, 73.

Komputer, Wahana. 2012. Mudah Membuat Portal Berita Online dengan $P H P$ dan $M y S Q L$, ANDI OFFSET dan Wahana, Yogyakarta dan Semarang.

Kadir, A. 2008. Dasar Pemrograman Web Dinamis Menggunakan PHP, ANDI, Yogyakarta.
MADCOMS, 2011. Membongkar Misteri Adobe Dreamweaver CS6 dengan $P H P \& M y S Q L$, ANDI OFFSET, Yogyakarta.

MADCOMS, 2009. Menguasai XHTML,CSS, PHP \& MySQL Melalui Dreamweaver, ANDI OFFSET, Yogyakarta.

Mukti, S. E. 2013. Rancang Bangun Aplikasi Bimbingan Akademik Berbasis Web dan Android pada Program Studi Manajemen S1 STIE MDP, 1-10.

Nugroho, Adi. 2010. Rekayasa Perangkat Lunak Berorientasi Objek dengan Metode USDP, ANDI OFFSET, Yogyakarta.

Nugroho, Bunafit. 2004. PHP dan MySQL dengan Editor Dreamweaver $M X$, ANDI, Yogyakarta

Pardosi, M. 2001. Bimbingan Belajar Internet, "INDAH" Surabaya, Surabaya.

Primasetya, G. 2013. Aplikasi Pengajuan Skripsi Mahasiswa Jurusan Sistem Informasi Universitas Gunadarma Berbasis Android, 1-13

Riyanto, 2011. Membuat sendiri aplikasi e-commerce dengan PHP \& MySQL menggunakan CodeIgniter \& Jquery, ANDI OFFSET, Yogyakarta.

Saputra, A. 2012. Trik Dahsyat Menjadi Web Master dengan Framework CakePHP, ANDI OFFSET, Yogyakarta.

Pressman, S. R. 2010. Rekayasa Perangkat Lunak, ANDI, Yogyakarta. Sitorus, I. 2012. Panduan Mudah Menjadi Programmer Web Menggunakan HTML, XHTML, dan CSS3, ANDI, Yogyakarta. 
Simarmata, J. 2010. Rekayasa Web, Andi, Yogyakarta.

STMIK Palangkaraya, 2014. Pedoman

Penulisan Proposal dan Skripsi

Teknik Informatika. Palangkaraya.

Wahidin, 2010. Aplikasi SMS dengan

PHP untuk Orang Awam, Maxikom, Palembang. 